\title{
Role of Common Gene Variations in the Molecular Pathogenesis of Short-Chain Acyl-CoA Dehydrogenase Deficiency
}

\author{
MORTEN JUHL CORYDON, JERRY VOCKLEY, PIERO RINALDO, WILLIAM JAMES RHEAD, \\ MARGRETHE KJELDSEN, VIBEKE WINTER, CHARLES RIGGS, \\ DUSICA BABOVIC-VUKSANOVIC, JAN SMEITINK, JAN DE JONG, HARVEY LEVY, \\ ADRIAN CLIVE SEWELL, CHARLES ROE, DIETRICH MATERN, MAJED DASOUKI, \\ AND NIELS GREGERSEN
}

\begin{abstract}
Research Unit for Molecular Medicine, Aarhus University Hospital and Faculty of Health Sciences, Skejby Sygehus, 8200 Aarhus N, Denmark [M.J.C., M.K., V.W., N.G.]; Department of Medical Genetics, Mayo Clinic and Foundation, Rochester, MN 55905, U.S.A. [J.V., D.B-V.]; Department of Laboratory Medicine \& Pathology, Mayo Clinic, Rochester, MN 55905, U.S.A. [P.R.]; Department of Pediatrics, University of Iowa, Iowa City, IA 50011, U.S.A. [W.J.R.]; Human Performance Laboratory, University of Arkansas, Fayetteville, AR 72701, U.S.A. [C.R.]; University Children's Hospital, Department of Metabolic Diseases, 6500 HB Nijmegen, The Netherlands [J.S., J.D.J.]; Division of Genetics, Children's Hospital, Boston, MA 02115, U.S.A. [H.L.]; University Children's Hospital, 60596 Frankfurt am

Main, Germany [A.C.S.]; Institute of Metabolic Disease, Dallas, TX 75226, U.S.A. [C.R.]; Division of Medical

Genetics, Department of Pediatrics, Duke University Medical Center, Durham, NC 27708, U.S.A. [D.M.]; Children's
\end{abstract} Mercy Hospital, Kansas City, MO 64108, U.S.A. [M.D.]

\section{ABSTRACT}

\begin{abstract}
Short-chain acyl-CoA dehydrogenase (SCAD) deficiency is considered a rare inherited mitochondrial fatty acid oxidation disorder. Less than 10 patients have been reported, diagnosed on the basis of ethylmalonic aciduria and low SCAD activity in cultured fibroblast. However, mild ethylmalonic aciduria, a biochemical marker of functional SCAD deficiency in vivo, is a common finding in patients suspected of having metabolic disorders. Based on previous observations, we have proposed that ethylmalonic aciduria in a small proportion of cases is caused by pathogenic SCAD gene mutations, and SCAD deficiency can be demonstrated in fibroblasts. Another - much more frequent - group of patients with mild ethylmalonic aciduria has functional SCAD deficiency due to the presence of susceptibility SCAD gene variations, i.e. $625 \mathrm{G}>\mathrm{A}$ and $511 \mathrm{C}>\mathrm{T}$, in whom a variable or moderately reduced SCAD activity in fibroblasts may still be clinically relevant. To substantiate this notion we performed sequence analysis of the SCAD gene
\end{abstract}

in 10 patients with ethylmalonic aciduria and diagnosed with SCAD deficiency in fibroblasts. Surprisingly, only one of the 10 patients carried pathogenic mutations in both alleles, while five were double heterozygotes for a pathogenic mutation in one allele and the $625 \mathrm{G}>$ A susceptibility variation in the other. The remaining four patients carried only either the $511 \mathrm{C}>\mathrm{T}$ or the $625 \mathrm{G}>\mathrm{A}$ variations in each allele. Our findings document that patients carrying these SCAD gene variations may develop clinically relevant SCAD deficiency, and that patients with even mild ethylmalonic aciduria should be tested for these variations. (Pediatr Res 49: 18-23, 2001)

EMA, ethylmalonic acid

\section{Abbreviations:}

SCAD, short, chain acyl-CoA dehydrogenase
Short-chain acyl-CoA dehydrogenase (SCAD) (EC 1.3.99.2) is the first enzyme of the mitochondrial short-chain $\beta$-oxidation spiral catalyzing the dehydrogenation of $\mathrm{C}_{4}$ and

Received March 22, 2000; accepted July 29, 2000.

Correspondence and reprint requests: Niels Gregersen, Research Unit for Molecular Medicine, Skejby Sygehus, Brendstrupgaardsvej, 8200 Aarhus N, Denmark.

The study was supported by the Danish Center for Human Genome Research, The Danish Medical Research Council, The Institute of Experimental Clinical Research and Aarhus County Research Initiative. Dr. Jerry Vockley was supported in part by U.S. Public Health Service Grant DKRO1-549361, and a grant from the March of Dimes Foundation.

Part of these findings were reported in preliminary form at the 36th Annual Symposium of the Society for the Study of Inborn errors of metabolism (York, U.K.), and at the 48th Annual Meeting of the American Society of Human Genetics (Denver, CO, U.S.A.).
$\mathrm{C}_{6}$ fatty acids (1). Inherited SCAD deficiency was first reported in 1987 (2). Since then only eight additional patients have been identified on the basis of reduced to absent enzymatic activity in vitro (3-10), and the biochemical finding of ethylmalonic aciduria (EMA aciduria), believed to have only limited specificity (11).

Following the report of the SCAD cDNA sequence (12), pathogenic mutations in both alleles of the SCAD gene were identified in one patient with SCAD deficiency (13). Subsequent studies of four unrelated patients with deficiency of SCAD enzyme activity in cultured skin fibroblasts led to the identification of three more pathogenic mutations in the SCAD gene, in addition 
to two variations, $625 \mathrm{G}>\mathrm{A}$ and $511 \mathrm{C}>\mathrm{T}(8,14,15)$. We showed that the $625 \mathrm{~A}$ and $511 \mathrm{~T}$ variant alleles, either in homozygous or in double heterozygous form, were over-represented $(69 \%$ versus $14 \%$ in the general population) among a clinically heterogeneous group of 133 patients with EMA aciduria. These observations lead to the hypothesis that the SCAD gene variations may represent susceptibility alleles $(8,16)$.

On the basis of these results, we proposed that patients with EMA aciduria could be divided into two groups: A small group of patients with pathogenic mutations in both alleles of the SCAD gene; and a second, much larger, group of subjects with in vivo functional SCAD deficiency who carry any combination of the $625 \mathrm{~A}$ and $511 \mathrm{~T}$ variant alleles. These individuals may have normal or moderately reduced enzyme activity in vitro under normal conditions, but may become symptomatic under the influence of additional genetic, cellular, and/or environmental factors.
To substantiate the validity of this classification we analyzed the SCAD gene in 10 patients with EMA aciduria and a confirmed SCAD deficiency in cultured skin fibroblast cells. Here we report the results of the mutation analyses in these 10 patients, and discuss the possible implications for the understanding of EMA aciduria and the diagnosis of SCAD deficiency.

\section{METHODS}

\section{Subjects}

Patients. Clinical and biochemical data of 10 unrelated patients with EMA aciduria and deficient SCAD activity in cultured fibroblasts are summarized in Table 1. Clinical reports of patients 6 and 10 have been published previously $(4,5)$.

Controls. Lymphoblastoid cells of 50 Danish controls were obtained from the cell bank repository of the Panum Institute

Table 1. Clinical, biochemical, enzymatic, and molecular data on 10 patients with EMA aciduria and SCAD deficiency

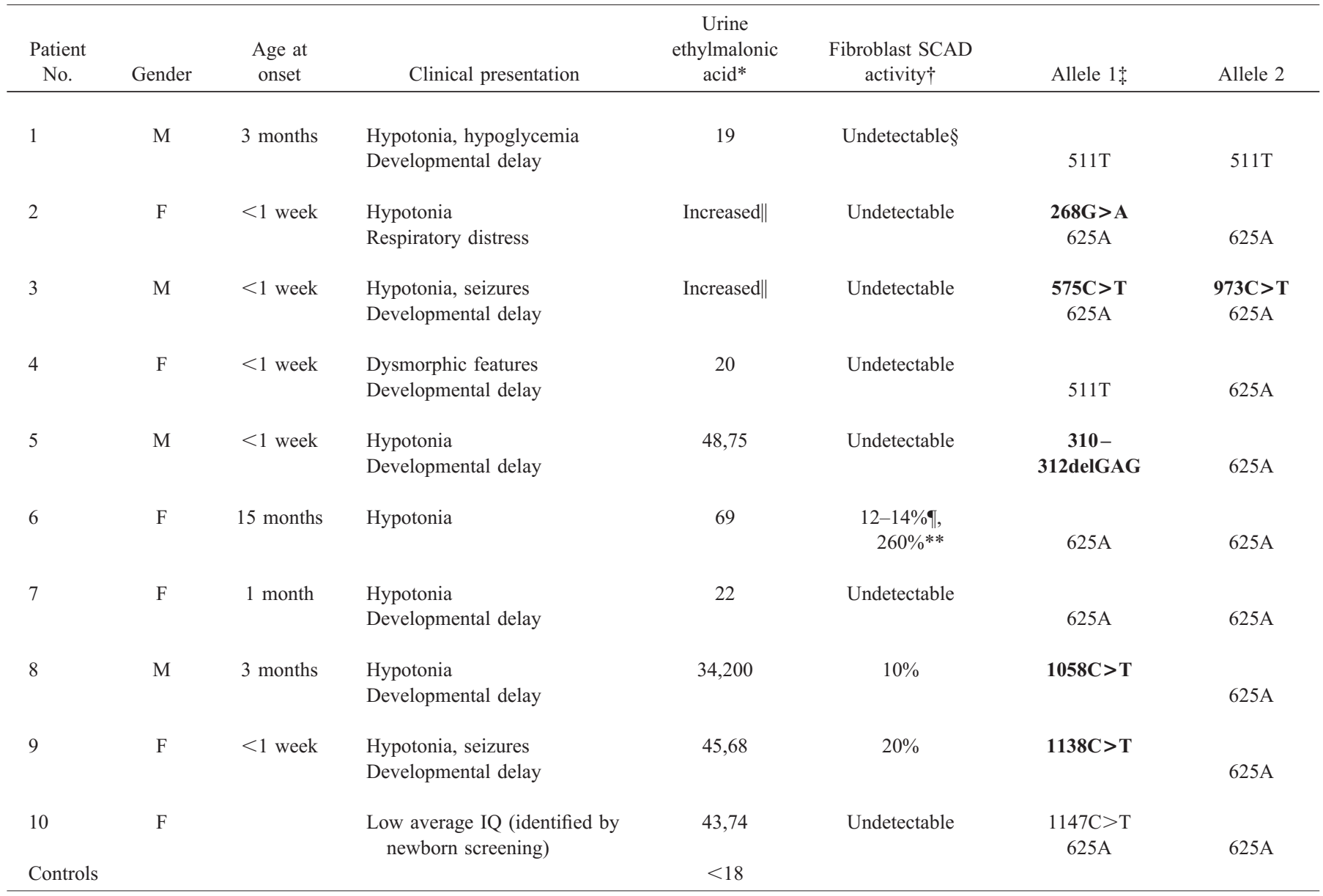

* $\mathrm{mmol} / \mathrm{mol}$ creatinine.

$\uparrow$ Data for patients represent percentage of control short-chain acyl-CoA dehydrogenase (SCAD) activity values after inclusion of anti medium-chain acyl-CoA

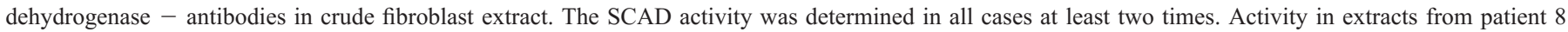

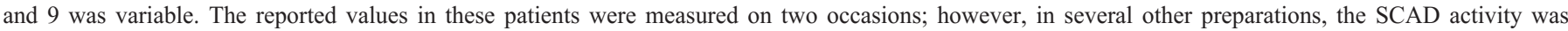

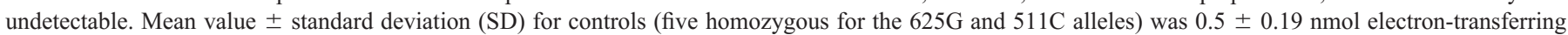
flavoprotein (ETF) reduced $/ \mathrm{mg}$ protein $/ \mathrm{min}(100 \pm 38 \%)$.

$\$$ cDNA numbering starts at the ATG translation initiation. The six new mutations are printed in bold.

$\S$ Undetectable represents $<10 \%$ of control SCAD activity.

$\|$ Increased based on qualitative evaluation and reporting of organic acid profile.

I Deficient activity in fibroblasts was reported previously $(4,23)$.

** SCAD activity value from this study.

Mutations in patients 6 and 10 have been reported previously in short $(14,15)$. 
(Copenhagen, Denmark). The appropriate human investigation committees in Denmark approved the use of this control material.

Analytical methods. EMA was determined by standard gas chromatography/mass spectrometry methods. SCAD activity was measured by the anaerobic electron-transferring flavoprotein (ETF) fluorescence-reduction assay (17). Immunoblotting of SCAD in human fibroblasts and Escherichia coli extract was performed using a rabbit anti-human SCAD antiserum (18). Genomic DNA was isolated from blood samples and cultured skin fibroblasts by standard methods (19). Fragments covering the SCAD 5'-flanking promoter-region and each of the 10 SCAD gene exons including flanking intron sequences were produced by PCR and sequenced in both directions (20). Total RNA was prepared from frozen patient fibroblasts using a RNAzol kit (WAK-Chemie, Bad Hornburg, Germany), and first-strand cDNA was synthesized from $1 \mu \mathrm{g}$ of total RNA using a commercial kit (Clontech, Palo Alto, CA). Fragments covering the full-length coding region of the SCAD cDNA were produced using previously described PCR conditions (8). PCR-generated cDNA fragments covering the full-length coding region were cloned into the pGEM-T vector (Promega, Madison, WI) and sequenced.

To express mutant proteins in E. coli, mutations were introduced by site-directed mutagenesis into the mature human SCAD cDNA cloned into the pSP64 vector (Promega), then transferred to an expression plasmid (pKK223-3, Pharmacia Biotech, Sweden) (21). Extracts were prepared and analyzed for SCAD enzyme activity and immunoreactive SCAD protein following $4 \mathrm{~h}$ induction with isopropylthiogalactoside.

\section{RESULTS}

Clinical findings. Contrary to previous reports of highly variable phenotypes associated with SCAD deficiency (3-10), more than half of the patients described in this report showed a phenotype with hypotonia (8/10) and developmental delay (7/10). Hypotonia was noticed shortly after birth in three cases, and within a few months in three additional patients. The oldest patient at the time of diagnosis was 15 month old. Other possible noncoincidental manifestations included hypoglycemia, seizures, dysmorphic features, and hypertonia. There was no correlation between the level of EMA aciduria and the severity of clinical symptoms.

Mutation analysis. Sequence analysis of all exons and flanking intron sequences in the SCAD gene revealed six new potentially pathogenic mutations (printed in bold in Table 1) and one previously reported (8) pathogenic mutation $(1147 \mathrm{C}>\mathrm{T}$, Table 1$)$ in six of the 10 patients. The 3 -bp deletion at position 310-312 of the cDNA sequence of patient 5 is the first deletion described in the SCAD gene. It results in the loss of a glutamine residue at position 80 of the mature SCAD protein. The other mutations were all missense $(268 \mathrm{G}>\mathrm{A}$, $575 \mathrm{C}>\mathrm{T}, 973 \mathrm{C}>\mathrm{T}, 1058 \mathrm{C}>\mathrm{T}, 1138 \mathrm{C}>\mathrm{T}$, and $1147 \mathrm{C}>\mathrm{T})$. Four of these were located within a $\mathrm{CpG}$ dinucleotide, recognized as a mutation hot-spot (22). The resulting missense mutant SCAD proteins are indicated in Table 2. None of these sequence alterations were present in the SCAD gene from 50 unrelated control individuals, supporting the potential pathogenic nature of the mutations.

The previously identified common SCAD gene variations, $625 \mathrm{G}>\mathrm{A}$ and $511 \mathrm{C}>\mathrm{T}$, which encode the $\mathrm{G} 185 \mathrm{~S}$ and $\mathrm{R} 147 \mathrm{~W}$ mutant proteins, respectively, were also found in various combinations with the rare mutations in the 10 patients (Table 1). One patient (patient 3 ) harbored two rare mutations, five had one mutation (patients 2, 5, 8, 9, and 10), and four had none (patients 1, 4, 6, and 7). The variation $625 \mathrm{G}>\mathrm{A}$ was found in nine of the patients (Table 1), five of whom were homozygous for this variation, while one was homozygous for the $511 \mathrm{C}>\mathrm{T}$ variation. Of the five cases homozygous for $625 \mathrm{G}>\mathrm{A}$, patients 6 and 7 did not harbor any other mutation in the cDNA sequence. Contrary to previous reports $(4,23)$, fibroblasts from patient 6 showed normal enzyme activity (Table 1), and had normal amounts of immunodetectable protein as well (results not shown). Patient 4 is likely a double heterozygote for the $511 \mathrm{C}>\mathrm{T}$ and $625 \mathrm{G}>\mathrm{A}$ variations, since we have previously shown that these variations are exclusively found in separate alleles (8).

The allelic assignment of the mutations in five of the patients (patients 1, 2, 6, 7, and 10) was obvious because of homozygosity for either the $511 \mathrm{C}>\mathrm{T}$ or the $625 \mathrm{G}>\mathrm{A}$ variations. Furthermore, each allele identified in patients 1 and 6 was identified in one of the parents, excluding the possibility of a gene deletion in one allele. To make allelic assignments of the mutations in the remaining five cases, cDNA made from patient fibroblast mRNA was cloned and sequenced. Each mutation was always found in separate clones (between 10 and 19 clones characterized per mutation), confirming the assignment of different mutations in each patient to different alleles.

In conclusion, all 10 patients harbored a rare mutation and/or one of the common variations in each allele of the SCAD gene, thus demonstrating the association between SCAD gene mutations/variations and SCAD deficiency.

Haplotype analysis. In addition to the new mutations and the previously identified missense variations, several additional neutral polymorphic variations were found in this cohort of patients: $321 \mathrm{~T}>\mathrm{C}, 990 \mathrm{C}>\mathrm{T}$ and $1260 \mathrm{G}>\mathrm{C}$ (24). Haplotypes could be inferred in all patients based on comparison with haplotypes defined in 34 independent control individuals from 17 families (father, mother, child), and the mutations and variations were assigned to a single known haplotype (Table 3 ) (24).

Sequence analysis of the SCAD 5'-flanking promoter-region in patients and controls revealed a previously unrecognized sequence variation, an $\mathrm{C}>\mathrm{A}$ substitution at position 171 upstream of the ATG start codon $(-171 \mathrm{C}>\mathrm{A})$. This variation is present in $38 \%$ of control individuals, and thus its functional significance is unclear. Inclusion of this variation in the previously defined haplotypes extended the total number of haplotypes present in the Danish population to 6 (Table 3). The inferred haplotypes of the 10 patients are included in Table 3, and it is obvious that haplotype II, which includes the $625 \mathrm{G}>\mathrm{A}$ and the $-171 \mathrm{C}>\mathrm{A}$ variations, is highly prevalent among the alleles in the patients as well as in the general population.

Functional analysis of mutations/variations. To evaluate the functional significance of the identified missense muta- 
Table 2. Expression of mutant and wild-type (control) SCAD proteins in E. coli at $37^{\circ} \mathrm{C}$ for $4 \mathrm{~h}$

\begin{tabular}{|c|c|c|}
\hline Mutation* & $\begin{array}{l}\text { Change in mature } \\
\text { SCAD protein }\end{array}$ & $\begin{array}{l}\text { Activity }(\text { nmol ETF reduced/mg } \\
\text { protein } / \mathrm{min}) \dagger\end{array}$ \\
\hline $268 \mathrm{G}>\mathrm{A}$ & G66S & Undetectable \\
\hline 310-312delGAG & E80del & Undetectable \\
\hline $575 \mathrm{C}>\mathrm{T}$ & A168V & Undetectable \\
\hline $973 \mathrm{C}>\mathrm{T}$ & $\mathrm{R} 301 \mathrm{~W}$ & Undetectable \\
\hline $1058 \mathrm{C}>\mathrm{T}$ & S329L & Undetectable \\
\hline $1138 \mathrm{C}>\mathrm{T}$ & R356W & Undetectable \\
\hline $511 \mathrm{C}>\mathrm{T}$ & $\mathrm{R} 147 \mathrm{~W}$ & 4.59 \\
\hline \multirow[t]{2}{*}{$625 \mathrm{G}>\mathrm{A}$} & G185S & 5.75 \\
\hline & Wild type & $6.66 \pm 0.71$ \\
\hline
\end{tabular}

* cDNA numbering starts at the ATG translation initiation and amino acid numbering at the cleavage site between leader peptide and mature protein.

$\dagger n=3$.

$\ddagger$ Undetectable represent $<0.05 \mathrm{nmol}$ electron-transferring flavoprotein (ETF) $\mathrm{reduced} / \mathrm{mg}$ protein $/ \mathrm{min}$.

tions, the wild-type (control) SCAD mature region, as well as inserts carrying the six rare mutations and the two common variations, were cloned into a prokaryotic expression vector. Following incubation at $37^{\circ} \mathrm{C}$ for $4 \mathrm{~h}$, crude cellular extracts were prepared and tested for SCAD activity (Table 2). Each of the five new missense mutations and the 3-bp deletion all result in proteins with no detectable enzyme activity, while Western blotting showed the presence of immunoreactive material in all the extracts (data not shown). These results confirm the inactivating nature of these mutations. One of the mutant proteins, R359C (encoded by the $1147 \mathrm{C}>\mathrm{T}$ mutation), seen in patient 10 has previously been expressed in COS-7 cells where similar results were obtained (8). In contrast, the G185S and R147W variant proteins encoded by the $625 \mathrm{~A}$ and $511 \mathrm{~T}$ variant alleles, respectively, showed $86 \%$ and $69 \%$ activity of the mean wildtype value, respectively, also in agreement with previous expression studies in COS-7 cells at the same temperature (8).

\section{DISCUSSION}

We have pursued the molecular characterization of 10 patients with biochemical and enzymatic findings consistent with a diagnosis of SCAD deficiency, an inborn error of metabolism considered to be a rare autosomal recessive disorder (25). In contrast to previous reports, the clinical presentations of the patients in this group were similar although rather nonspecific, with hypotonia and developmental delay as prevalent features. The presence of other very different clinical pictures in these patients (Table 1) and in the previously published cases could indicate a selection bias in the patients described here, and it emphasizes the current difficulties of recognizing patients with this kind of fatty acid oxidation disorder solely on the basis of clinical findings (26).

It is surprising that only one patient (patient 3, Table 1) carried two pathogenic mutations, as indicated by their nonpresence in 100 control alleles, and defined by complete loss of enzyme activity of the mutant protein produced in a prokaryotic expression system. The remaining patients were double heterozygous for a pathogenic mutation and the previously identified $625 \mathrm{G}>\mathrm{A}$ variation, homozygous for one of the variations, $625 \mathrm{G}>\mathrm{A}$ or $511 \mathrm{C}>\mathrm{T}$, or double heterozygous for both of them.

It is noteworthy that four alleles in three of the patients $(2$, 3 , and 10) in addition to a pathogenic mutation carry the $625 \mathrm{G}>\mathrm{A}$ variation. This could suggest a synergy in the effects, although our present understanding is that the effect of pathogenic mutations eliminates the effect of the variation as indicated by the prokaryotic expression studies. The identification of further similar alleles in patients with SCAD deficiency are needed to evaluate whether they are truly overrepresented, and if so, further cell studies in eucaryotic cells may reveal a possible biologic significance.

The analysis of the haplotypes, defined by the three previously identified neutral SCAD gene variations $(321 \mathrm{~T}>\mathrm{C}$, $990 \mathrm{C}>\mathrm{T}$, and $1260 \mathrm{G}>\mathrm{C}$ ), the new variation in the promoter of the SCAD gene $(-171 \mathrm{C}>\mathrm{A})$, and the $625 \mathrm{G}>\mathrm{A}$ and $511 \mathrm{C}>\mathrm{T}$ variations gives a total of 6 haplotypes in the general population (Table 3; the previously defined haplotype I (24) is now divided in IA and IB). Interestingly, the haplotype in the patients with one or two $625 \mathrm{G}>\mathrm{A}$ variations (designated II) can be identified in 15 of the 68 alleles in the general population, while seven of 68 control alleles are haplotype IB which harbors the $511 \mathrm{C}>\mathrm{T}$ variation. This indicates that the genetic background - defined by these haplotypes - is not likely to contribute significantly to the apparent pathogenesis related to the $625 \mathrm{G}>\mathrm{A}$ or $511 \mathrm{C}>\mathrm{T}$ variations.

In contrast to the severe effect of the six rare mutations on the SCAD enzyme activity, the R147W and G185S variant enzymes showed only a modest reduction in enzymatic activity when produced in E. coli. These findings are compatible with previously reported expression studies in COS-7 cells (8), where the enzymatic properties of the two variant proteins were found to be temperature-dependent. In these experiments a shift of temperature of the COS-7 cell expression system

Table 3. Haplotypes in the SCAD gene in 34 independent control individuals from 17 families (father, mother, child)

\begin{tabular}{|c|c|c|c|c|c|c|c|c|c|}
\hline Haplotype & $\begin{array}{l}\text { Frequency } \\
\text { Denmark* }\end{array}$ & $-171 \dagger$ & 321 & 511 & 625 & 990 & 1260 & Identified mutations & $\begin{array}{l}\text { Frequency } \\
10 \text { patients* }\end{array}$ \\
\hline IA & $33 / 68$ & $\mathrm{C}$ & $\mathrm{T}$ & $\mathrm{C}$ & G & $\mathrm{C}$ & G & & $0 / 20$ \\
\hline IB & $7 / 68$ & $\mathrm{C}$ & $\mathrm{T}$ & $\mathrm{T}$ & G & $\mathrm{C}$ & G & & $3 / 20$ \\
\hline III & $11 / 68$ & A & $\mathrm{C}$ & $\mathrm{C}$ & G & $\mathrm{T}$ & G & $310-312$ delGAG; $1058 \mathrm{C}>\mathrm{T} ; 1138 \mathrm{C}>\mathrm{T}$ & $3 / 20$ \\
\hline IV & $1 / 68$ & $\mathrm{C}$ & $\mathrm{T}$ & $\mathrm{C}$ & G & $\mathrm{C}$ & $\mathrm{C}$ & & $0 / 20$ \\
\hline $\mathrm{V}$ & $1 / 68$ & $\mathrm{C}$ & $\mathrm{T}$ & $\mathrm{C}$ & A & $\mathrm{C}$ & $\mathrm{C}$ & & $0 / 20$ \\
\hline
\end{tabular}

* Haplotype frequencies in 34 controls (68 alleles) and in the 10 analyzed patients (20 alleles) with EMA aciduria and SCAD deficiency.

$\dagger$ Positions are relative to the start codon of SCAD cDNA.

$\ddagger$ The pathogenic mutations are assigned to the haplotypes. 
from $37^{\circ} \mathrm{C}$ to $41{ }^{\circ} \mathrm{C}$ caused a reduction of SCAD activity to $13 \%$ and $58 \%$ of control activity, respectively, for the R $147 \mathrm{~W}$ and $\mathrm{G} 185 \mathrm{~S}$ variant proteins, while a reduction of temperature to $26^{\circ} \mathrm{C}$ led to an increase of activity to $85 \%$ and $183 \%$ relative to wild-type, respectively. Thus, the activity of the two variant proteins is dependent on cellular conditions, a phenomenon previously documented for other SCAD and medium-chain acyl-CoA dehydrogenase (MCAD) mutant proteins (27-29). In this regard, it is interesting to note that we have found the measurements of SCAD activity in cultured fibroblasts from individuals carrying the variant alleles to be somewhat variable (unpublished results). A striking example of this can be seen in patient 6 , who previously was diagnosed with SCAD deficiency based on assay of fibroblast extract $(4,23)$. The conditions leading to this variability are currently under further investigation. Preliminary results indicate that the amounts of SCAD antigen in fibroblasts from patients carrying the $625 \mathrm{~A}$ variant allele may vary as much as the enzyme activity, probably reflecting the structural instability of either folding intermediates and/or the final active enzyme.

In total, these findings suggest that the $625 \mathrm{G}>A$ and $511 \mathrm{C}>\mathrm{T}$ variations are unlikely to lead to clinically relevant SCAD deficiency in and of themselves. Rather, we postulate that other genetic, cellular, and environmental factors must be involved in reducing the level of catalytic activity of the variant enzymes below a critical threshold, leading to the onset of clinical symptoms. Depending on the nature of these factors, a deficiency may either be consistently expressed or related to intermittent cellular stress (such as elevated temperature or reduced $\mathrm{pH}$ ), or variable efficiency of the cellular protein handling system (30).

In retrospect, the possibility that the common variations might predispose to clinical disease was first suggested by the report of a patient who was a double heterozygote for a pathogenic mutation and the $511 \mathrm{C}>\mathrm{T}$ variation (8). This original interpretation is now convincingly supported by the isolated finding of 511C $>\mathrm{T}$ homozygosity in a patient with completely deficient enzymatic activity (patient 1, Table 1). Overall, the two common variations were found in 17/20 $(85 \%)$ of the alleles in 10 patients with reduced fibroblast SCAD activity. A similar over-representation of these alleles was found in a study of 133 subjects with EMA aciduria (8, 16), indicative of an in vivo functional SCAD deficiency, suggesting that SCAD deficiency in fibroblast could probably have been demonstrated in some of these individuals.

The current study shows the need for a substantial revision of our thinking regarding the role played by the $625 \mathrm{G}>\mathrm{A}$ and $511 \mathrm{C}>\mathrm{T}$ variations in the etiology of SCAD deficiency. Since these variations are found either in homozygous or double heterozygous form in $14 \%$ of the general population (8), the actual incidence of clinically relevant SCAD deficiency could be much higher than currently recognized, possibly becoming one of the most common inborn errors of metabolism known to date. Prospective clinical studies are necessary to establish the true incidence of clinically relevant SCAD deficiency and to define the spectrum of its clinical manifestations from the newborn to the geriatric patient. Until such studies are completed our operative recommendation is to investigate every patient with elevated EMA ( $>18 \mu \mathrm{mol} / \mathrm{mmol}$ creatinine) for the two variations $625 \mathrm{G}>\mathrm{A}$ and $511 \mathrm{C}>\mathrm{T}$. If either is present in homozygous form or the patient is double heterozygous for them we recommend treatment similar to other fatty acid oxidation deficiencies. If the variations are not present or only in one allele we consider investigation of the whole SCAD gene sequence.

Before we know more about the pathogenesis of the variations and the natural history of children identified with possible SCAD deficiency by the emerging neonatal screening programs for acyl-carnitines, we recommend being very conservative in testing for these variations. As long as we do not know whether other genetic factors contribute to the disease expression and outcome, testing for these variations should be restricted to clinically symptomatic patients of any age with otherwise unexplained manifestations and elevated excretion of ethylmalonic acid.

Acknowledgments. The authors thank Kay Tanaka, Yale University, for the gift of the anti-SCAD antibody. We also thank Dr. Hans Eiberg for providing DNA from control individuals and Medical Laboratory Technologist Anette Thomsen for taking care of patient cells.

\section{REFERENCES}

1. Finocchiaro G, Ito M, Tanaka K 1988 Purification and properties of short-chain acyl-CoA, medium-chain acyl-CoA, and isovaleryl-CoA dehydrogenases from human liver. Adv Neurol 48:221-230

2. Amendt BA, Greene C, Sweetman L, Cloherty J, Shih V, Moon A, Teel L, Rhead WJ 1987 Short-chain acyl-coenzyme A dehydrogenase deficiency. Clinical and biochemical studies in two patients. J Clin Invest 79:1303-1309

3. Coates PM, Hale DE, Finocchiaro G, Tanaka K, Winter SC 1988 Genetic deficiency of short-chain acyl-coenzyme A dehydrogenase in cultured fibroblasts from a patient with muscle carnitine deficiency and severe skeletal muscle weakness. J Clin Invest 81:171-175

4. Sewell AC, Herwig J, Bohles H, Rinaldo P, Bhala A, Hale DE 1993 A new case of short-chain acyl-CoA dehydrogenase deficiency with isolated ethylmalonic aciduria. Eur J Pediatr 152:922-924

5. Bhala A, Willi SM, Rinaldo P, Bennett MJ, Schmidt-Sommerfeld E, Hale DE 1995 Clinical and biochemical characterization of short-chain acyl-coenzyme A dehydrogenase deficiency. J Pediatr 126:910-915

6. Dawson DB, Waber L, Hale DE, Bennett MJ 1995 Transient organic aciduria and persistent lacticacidemia in a patient with short-chain acyl-coenzyme A dehydrogenase deficiency. J Pediatr 126:69-71

7. Baerlocher KE, Steinmann B, Aguzzi A, Krähehbühl S, Roe CR, Vianey-Saban C 1997 Short-chain acyl-CoA dehydrogenase deficiency in a 16-year-old girl with severe muscle wasting and scoliosis. J Inherit Metab Dis 20:427-431

8. Gregersen N, Winter VS, Corydon MJ, Corydon TJ, Rinaldo P, Ribes A, Martinez G, Bennett MJ, Vianey-Saban C, Bhala A, Hale DE, Lehnert W, Kmoch S, Roig M, Riudor E, Eiberg H, Andresen BS, Bross P, Bolund LA, Kølvraa S 1998 Identification of four new mutations in the short-chain acyl-CoA dehydrogenase (SCAD) gene in two patients: one of the variant alleles, $511 \mathrm{C} \rightarrow \mathrm{T}$, is present at an unexpectedly high frequency in the general population, as was the case for $625 \mathrm{G} \rightarrow \mathrm{A}$, together conferring susceptibility to ethylmalonic aciduria. Hum Mol Genet 7:619-627

9. Ribes A, Riudor E, Garavaglia B, Martinez G, Arranz A, Invernizzi F, Briones P, Lamantea E, Sentis M, Barcelo A, Roig M 1998 Mild or absent clinical signs in twin sisters with short-chain acyl-CoA dehydrogenase deficiency. Eur J Pediatr 157:317320

10. Tein I, Haslam RH, Rhead WJ, Bennett MJ, Becker LE, Vockley J 1999 Short-chain acyl-CoA dehydrogenase deficiency: a cause of ophthalmoplegia and multicore myopathy. Neurology 52:366-372

11. Duran M, Walther FJ, Bruinvis L, Wadman SK 1983 The urinary excretion of ethylmalonic acid: what level requires further attention? Biochem Med 29:171-175

12. Naito E, Ozasa H, Ikeda Y, Tanaka K 1989 Molecular cloning and nucleotide sequence of complementary DNAs encoding human short chain acyl-coenzyme A dehydrogenase and the study of the molecular basis of human short chain acylcoenzyme A dehydrogenase deficiency. J Clin Invest 83:1605-1613

13. Naito E, Indo Y, Tanaka K 1990 Identification of two variant short chain acylcoenzyme A dehydrogenase alleles, each containing a different point mutation in a patient with short chain acyl-coenzyme A dehydrogenase deficiency. J Clin Invest 85:1575-1582

14. Kristensen MJ, Bross P, Bhala A, Hale DE, Jensen TG, Gregersen N 1993 New point mutations in short-chain acyl-CoA dehydrogenase. Am J Hum Genet 53:915A 
15. Kristensen MJ, Kmoch S, Bross P, Andresen BS, Gregersen N 1994 Amino acid polymorphism (Gly209Ser) in the ACADS gene. Hum Mol Genet 3:1711

16. Corydon MJ, Gregersen N, Lehnert W, Ribes A, Rinaldo P, Kmoch S, Christensen E, Kristensen TJ, Andresen BS, Bross P, Winter V, Martinez G, Neve S, Jensen TG, Bolund L, Kølvraa S 1996 Ethylmalonic aciduria is associated with an amino acid variant of short-chain acyl-coenzyme A dehydrogenase. Pediatr Res 39:1059-1966

17. Frerman FE, Goodman SI 1985 Fluorometric assay of acyl-CoA dehydrogenase in normal and mutant human fibroblasts. Biochem Med 33:38-44

18. Ikeda Y, Okamura-Ikeda K, Tanaka K 1985 Purification and characterization of short-chain, medium-chain, and long-chain acyl-CoA dehydrogenases from rat liver mitochondria. Isolation of the holo- and apoenzymes and conversion of the apoenzyme to the holoenzyme. J Biol Chem 260:1311-1325

19. Gustafson S, Proper JA, Bowie EJ, Sommer SS 1987 Parameters affecting the yield of DNA from human blood. Anal Biochem 165:294-299

20. Corydon MJ, Andresen BS, Bross P, Kjeldsen M, Andreasen PH, Eiberg H, Kølvraa S, Gregersen N 1997 Homo sapiens SCAD gene, 5'-UTR and exon 1 to 10 (European Molecular Biology Laboratory/GenBank/DNA Data Bank of Japan; nucleotide sequence database accession no Z80345, Z80347)

21. Brosius J, Holy A 1984 Regulation of ribosomal RNA promoters with a synthetic lac operator. Proc Natl Acad Sci U S A 81:6929-6933

22. Barker D, Schafer M, White R 1984 Restriction sites containing CpG show a higher frequency of polymorphism in human DNA. Cell 36:131-138

23. Niezen-Koning KE, Wanders RJ, Nagel GT, Sewell AC, Heymans HS 1994 Measurement of short-chain acyl-CoA dehydrogenase (SCAD) in cultured skin fibroblasts with hexanoyl-CoA as a competitive inhibitor to eliminate the contribution of medium-chain acyl-CoA dehydrogenase. Clin Chim Acta 229:99-106
24. Corydon MJ, Andresen BS, Bross P, Kjeldsen M, Andreasen PH, Eiberg H, Kølvraa S, Gregersen N 1997 Structural organization of the human short-chain acyl-CoA dehydrogenase gene. Mamm Genome 8:922-926

25. Scriver CR 1995 Summery table. In: Scriver CR, Beaudet AL, Sly WS, Valle D (eds) The Metabolic and Molecular Bases of Inherited Disease. McGraw-Hill, New York 26. Rinaldo P, Raymond K, al Odaib A, Bennett MJ 1998 Clinical and biochemical features of fatty acid oxidation disorders. Curr Opin Pediatr 10:615-621

27. Corydon TJ, Bross P, Jensen TG, Corydon MJ, Lund TB, Jensen UB, Kim J-J, Gregersen N, Bolund L 1998 Rapid degradation of short-chain acyl-CoA dehydrogenase (SCAD) variants with temperature-sensitive folding defects occur after import into mitochondria. J Biol Chem 273:13065-13071

28. Bross P, Jespersen C, Jensen TG, Andresen BS, Kristensen MJ, Winter V, Nandy A, Krautle F, Ghisla S, Bolund L, Kim JJP, Gregersen N 1995 Effects of two mutations detected in medium chain acyl-CoA dehydrogenase (MCAD)-deficient patients on folding, oligomer assembly, and stability of MCAD enzyme. J Biol Chem 270:10284-10290

29. Andresen BS, Bross P, Udvari S, Kirk J, Gray J, Kmoch S, Chamoles N, Knudsen I, Winter V, Wilcken B, Yokota I, Hart K, Packman S, Harpey JP, Saudubray JM, Hale DE, Bolund L, Kølvraa S, Gregersen N 1997 The molecular basis of medium-chain acyl-CoA degydrogenase (MCAD) deficiency in compound heterozygous patients: Is there correlation between genotype and phenotype? Hum Mol Genet 6:695-707

30. Bross P, Corydon TJ, Andresen BS, Jørgensen MM, Bolund L, Gregersen N 1999 Protein misfolding and degradation in genetic disease. Hum Mutat 14:186198 